\title{
Modeling of Six Pulse Voltage Source Inverter based STATCOM with PWM and Conventional Triggering
}

\author{
Sachin Sharma, Alok Pandey, Nitin Kumar Saxena* \\ MIT Moradabad, UP India \\ e-mail: nitinsaxena.iitd@gmail.com
}

\begin{abstract}
In the present study, a six pulse inverter is triggered using conventional sequential and pulse width modulation (PWM) technique simultaneously for comparing their results. FACTS devices such as STATCOM are the most emerging areas in today's power system. This STATCOM is a power electronic based converter circuit in which inverter circuit is fabricated for the purpose of voltage control and reactive power compensation through its current flow. A six pulse inverter is developed that can be generalized for developing any number of multiple of six pulse inverters by cascading them in parallel using transformers connection. Voltage source Inverter (VSI) is the most commonly used inverter that can be modeled for electrical system based studies. A methodology is presented to trigger the STATCOM inverter circuit using conventional and PWM techniques, and then the results are compared using MATLAB simulink model.
\end{abstract}

Keywords: Six Pulse Voltage Source Inverter, IGBT, DC source, PWM, Active and Reactive Power

\section{Introduction}

In today's scenario the different kind of industrial machines, household electronic gadgets design to operate with AC but their operating performances go down due to the various power quality issues. The use of power electronic devices are the major cause for poor output waveform. In industry the required AC is actually converted by rectified DC which contains the harmonics which leads electrical power and temperature losses [1,2]. Thus a suitable converter is used after filtering the rectified DC to operate AC operated gadgets [3]. In industry mostly inverter takes input from rectifiers and they have further convert into $A C$ at usable places. Also FACT DEVICES which are playing an important role in power quality improvement in power transmission and renewable energy transmission systems are also uses the six pulse voltage source inverters for transmission of power [4]. And in dc power transmission system the ac power first rectified and then transmitted over the long distances but for use of ac power at domestic and industrial level a circuit is required to convert it into ac so voltage source inverter is also uses for the purpose of converting the power in power transmission system. A six pulse voltage source inverter gives an ac wave nearly equal to the sine wave which can further be used in many applications [5-8]. A six pulse voltage source inverter is can be consist thyristors, GTOs, IGBTs such devices. Here we used the fully controlled devices i.e. IGBT. The circuit consist six IGBTs (Insulator Gate Bipolar Transistor), a dc source and triggering circuits. A single phase inverter are also exists but three phase is familiar in industrial applications. Six pulse voltage source inverter is also be used in power grid devices like in STATCOM as converter circuit to provide six pulse ac to the flexible transmission lines. And this six pulse ac power can be increase by means of pulse by cascading the inverter $[9,10]$.

\section{Three Phase Six Pulse Voltage Source Inverter (VSI)}

The three phase six pulse voltage source inverter is used to convert the DC power into AC power at adjustable frequency. And the inverter can be used for providing ac supply to 3 phase load or gadgets and it can be used as the converter in STATCOM, a FACTS device. Figure 1 shows the basic block diagram of conversion of power in industry or in power transmission system.

VSI is an important part of STATCOM for conversion of power used in power system. Figure 2 shows the basic block diagram of STATCOM using six pulse VSI connected to power transmission system. 
Here we uses the IGBT based VCI, IGBTs are fully control device and they are turned $\mathrm{ON}$ only for the duration during which a gate pulse is given to it. The Figure 3 shows the basic diagram of a six pulse three- phase inverter. In this model, six IGBTs are connected in such a way that each phase of 3-Phase balance load is connected in middle of two IGBTs and they are triggered properly in a particular sequence as the name with number given to each IGBT. And another side is connected to the DC voltage source. A six pulse VSI has less harmonic content than that of directly obtained single pulse ac [11].

Conversion of firing angle in time scale from radian or degree is required for MATLAB simulink model and therefore, for $50 \mathrm{~Hz}$ frequency system, firing angle can be expressed in time scale using the expression given in Equation (1). Table 1 represents the firing angle conversion in time scale using this expression.

$X_{t}=\frac{0.02}{360} X_{d}$

Where,

$\mathrm{X}_{\mathrm{t}}$ : Firing angle in time scale

$X_{d}$ : Firing angle in degree

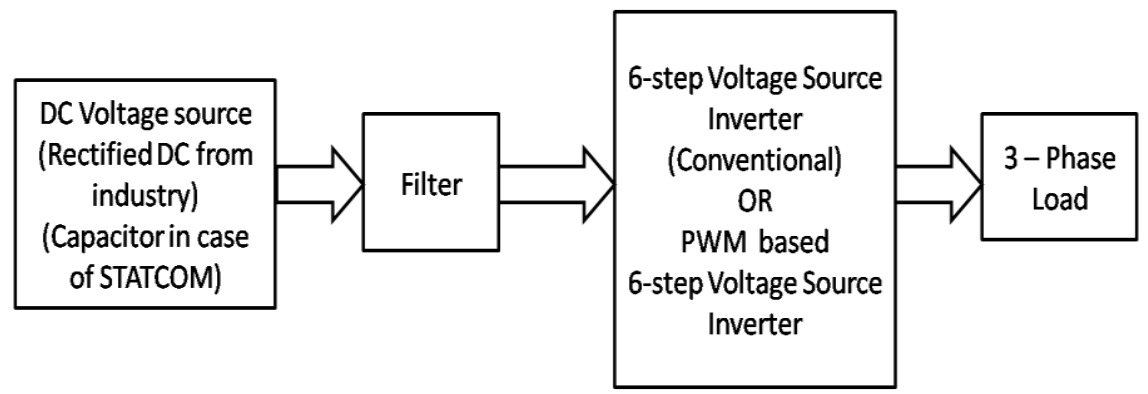

Figure 1. Block diagram of VSI connected to 3- Phase load

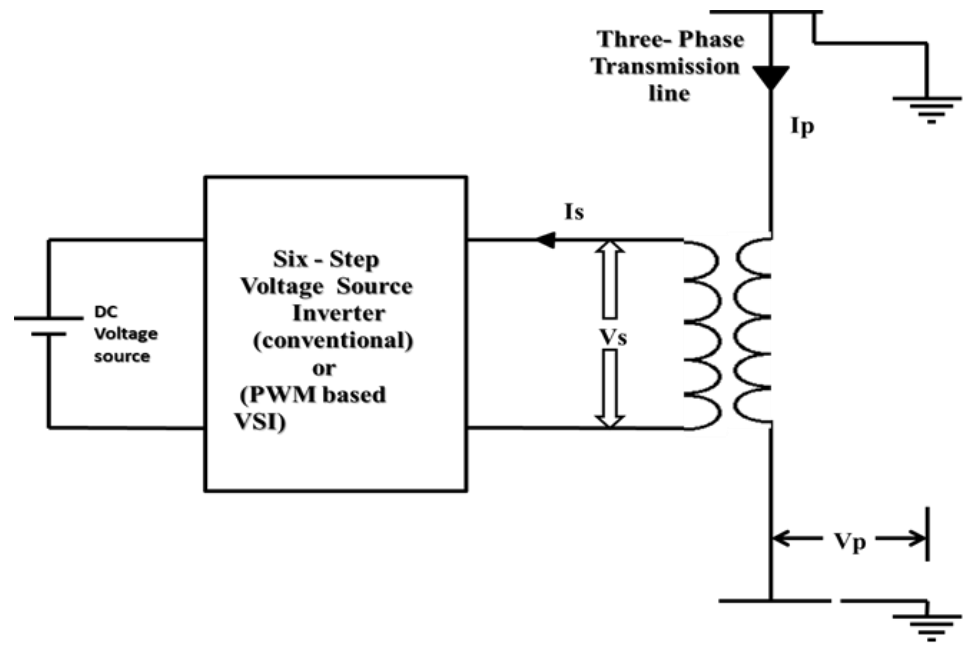

Figure 2. Block diagram of VCI connected as a element of STATCOM. 

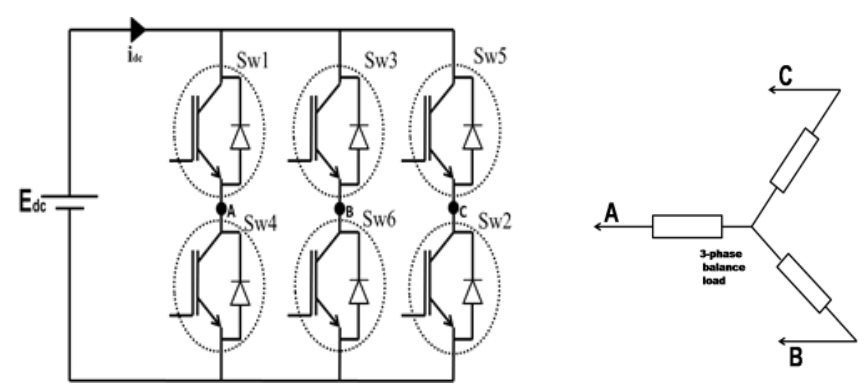

Figure 3. Basic structure of three-phase six-pulse voltage source inverter.

Table 1. Angles of triggering and their corresponding time values.

\begin{tabular}{ccc}
\hline No. & $\begin{array}{c}\text { Firing angle } \\
\text { (Angle) }\end{array}$ & $\begin{array}{c}\text { Correspond value } \\
\text { in time scale }\end{array}$ \\
\hline 1. & 300 & 0.00167 \\
2. & 600 & 0.00333 \\
3. & 900 & 0.005 \\
4. & 1200 & 0.0067 \\
5. & 1500 & 0.0083 \\
6. & 1800 & 0.01 \\
7. & 2100 & 0.0116 \\
8. & 2400 & 0.0133 \\
9. & 2700 & 0.015 \\
10. & 3000 & 0.0167 \\
11. & 3300 & 0.0183 \\
12. & 3600 & 0.02 \\
\hline
\end{tabular}

The voltage source inverter may work in two different possible modes. In one mode, each IGBT conducts for $180 \mathrm{o}$ and in another mode each IGBT conducts for $120 \mathrm{o}$. In $180 \mathrm{o}$ mode the gate pulses are given continuously for 180 o to each IGBT and in 120 o mode the gate pulses are given continuously for 120 o to each IGBT. A triggering sequence is the important factor that must be in consideration for smooth conduction of six pulse output [12, 13].

\section{Working Methodology}

\subsection{Operation of VSI for $180^{\circ}$ mode}

In 1800 mode of operation three IGBTs are worked together at the same time. The pulses are given for the $50 \%$ duration of a complete cycle. Each works for every 600 of a complete cycle with the help of specific triggering operation, in which gating signals are applied and removed at 600 intervals. The triggering operation on which IGBTs work sequentially is shown on the following Table 2. In 1800 mode of operation, Table 3 shows the sequence of triggered IGBTs in each cycle of 60o. Their corresponding output phase voltages are also mentioned in this Table.

Table 2. The angles duration for which corresponding IGBTs are in working

\begin{tabular}{|c|c|c|c|c|c|c|}
\hline \multirow{3}{*}{$\begin{array}{l}\text { Conducting } \\
\text { Switch }\end{array}$} & Sw1 & Sw1 & Sw1 & Sw4 & Sw4 & Sw4 \\
\hline & Sw6 & Sw6 & Sw3 & Sw3 & Sw3 & Sw6 \\
\hline & Sw5 & Sw2 & Sw2 & Sw2 & Sw5 & Sw5 \\
\hline $\begin{array}{c}\text { Angle } \\
\text { Duration }\end{array}$ & $\begin{array}{c}0^{\circ} \\
\text { to } \\
60^{\circ}\end{array}$ & $\begin{array}{c}60^{\circ} \\
\text { to } \\
120^{\circ}\end{array}$ & $\begin{array}{c}120^{\circ} \\
\text { to } \\
180^{\circ}\end{array}$ & $\begin{array}{c}180^{\circ} \\
\text { to } \\
240^{\circ}\end{array}$ & $\begin{array}{c}240^{\circ} \\
\text { to } \\
300^{\circ}\end{array}$ & $\begin{array}{c}300^{\circ} \\
\text { To } \\
360^{\circ}\end{array}$ \\
\hline
\end{tabular}


Table 3. Values of three phase voltages corresponding to input dc voltage and the working switches

\begin{tabular}{|c|c|c|c|}
\hline \multicolumn{3}{|c|}{ Phase Voltages } & \multirow{2}{*}{ Conducting Switch } \\
\hline AN & $\mathrm{BN}$ & $\mathrm{CN}$ & \\
\hline $\begin{array}{c}V_{s} / 3 \\
2 V s / 3 \\
V s / 3\end{array}$ & $\begin{array}{l}-2 V s / 3 \\
-V s / 3 \\
V s / 3\end{array}$ & $\begin{array}{c}\mathrm{Vs} / 3 \\
-\mathrm{Vs} / 3 \\
-2 \mathrm{~V} / 3\end{array}$ & {$[1,6.5]$} \\
\hline$-V s / 3$ & $2 \mathrm{Vs} / 3$ & $-V s / 3$ & {$\left[\begin{array}{l}{[1,3,2]} \\
{[4,3,2]}\end{array}\right.$} \\
\hline$-2 V s / 3$ & $\mathrm{Vs} / 3$ & $\mathrm{Vs} / 3$ & {$[4,3,5]$} \\
\hline$-V s / 3$ & $-V s / 3$ & $2 \mathrm{Vs} / 3$ & {$[4,6,5]$} \\
\hline
\end{tabular}

\subsection{Operation of VSI for $120^{\circ}$ mode}

In 120 o mode of operation two IGBTs are worked together at the same time. The pulses are given for $33.33 \%$ of the full cycle. Each works for every 600 of a complete cycle with the help of specific triggering operation, in which gating signals are applied and removed at 600 intervals. The triggering operation on which the IGBTs works sequentially is shown on the following Table 4 . In 1200 mode of operation, Table 5 shows the sequence of triggered IGBTs in each cycle of 600 . Their corresponding output phase voltages are also mentioned in this Table.

Table 4. The angles duration for which corresponding IGBTs are in working

\begin{tabular}{ccccccc}
\hline \multirow{3}{*}{ Conducting Switch } & Sw1 & Sw1 & Sw2 & Sw4 & Sw4 & Sw5 \\
& Sw6 & Sw2 & Sw3 & Sw3 & Sw5 & Sw6 \\
\hline Angle & $0^{\circ}$ & $60^{\circ}$ & $120^{\circ}$ & $180^{\circ}$ & $240^{\circ}$ & $300^{\circ}$ \\
Duration & to & to & to & to & to & to \\
& $60^{\circ}$ & $120^{\circ}$ & $180^{\circ}$ & $240^{\circ}$ & $300^{\circ}$ & $360^{\circ}$ \\
\hline
\end{tabular}

Table 5. Values of three phase voltages corresponding to input dc voltage and the working switches

\begin{tabular}{cccc}
\hline \multicolumn{3}{c}{ Phase Voltages } & \\
$\mathrm{AN}$ & $\mathrm{BN}$ & $\mathrm{CN}$ & Conducting Switch \\
\hline $\mathrm{Vs} / 3$ & $-2 \mathrm{Vs} / 3$ & $\mathrm{Vs} / 3$ & {$[1,6]$} \\
$2 \mathrm{Vs} / 3$ & $-\mathrm{Vs} / 3$ & $-\mathrm{Vs} / 3$ & {$[1,2]$} \\
$\mathrm{Vs} / 3$ & $\mathrm{Vs} / 3$ & $-2 \mathrm{Vs} / 3$ & {$[3,2]$} \\
$-\mathrm{Vs} / 3$ & $2 \mathrm{Vs} / 3$ & $-\mathrm{Vs} / 3$ & {$[4,3]$} \\
$-2 \mathrm{Vs} / 3$ & $\mathrm{Vs} / 3$ & $\mathrm{Vs} / 3$ & {$[4,5]$} \\
$-\mathrm{Vs} / 3$ & $-\mathrm{Vs} / 3$ & $2 \mathrm{Vs} / 3$ & {$[6,5]$} \\
\hline
\end{tabular}

\subsection{VSI triggering using PWM}

In this method a PWM generator is modeled for triggering purpose. This is achieved by comparing sine wave with repeated sequence signal. VSI give the output voltages in the form of modulated voltages [14]. Figure 4 gives a basic block diagram of VSI triggering circuit using PWM.

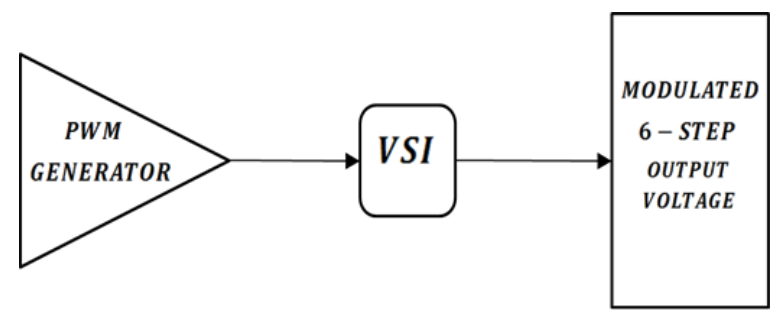

Figure 4. Block Diagram of triggering of VSI by PWM generator. 


\section{Developement Of Simulink Models}

For the study of six pulses VSI two methods as discussed above are modeled. In first model conventional triggering method is used in which six IGBTs are triggered individually by pulse generator in a right sequence of 600 phase difference. A complete simulink model is represented in Figure 5. A 100 volt dc source is connected to convert into ac through this inverter. A three phase resistive load is connected to output side. The diagram also a three vase measurement block which measures the output three phase (phase to ground) voltages and current whose result is shown on scope. There is also an active and reactive power measurement block which measures the active and reactive powers which further measures individually by the use of DMUX.

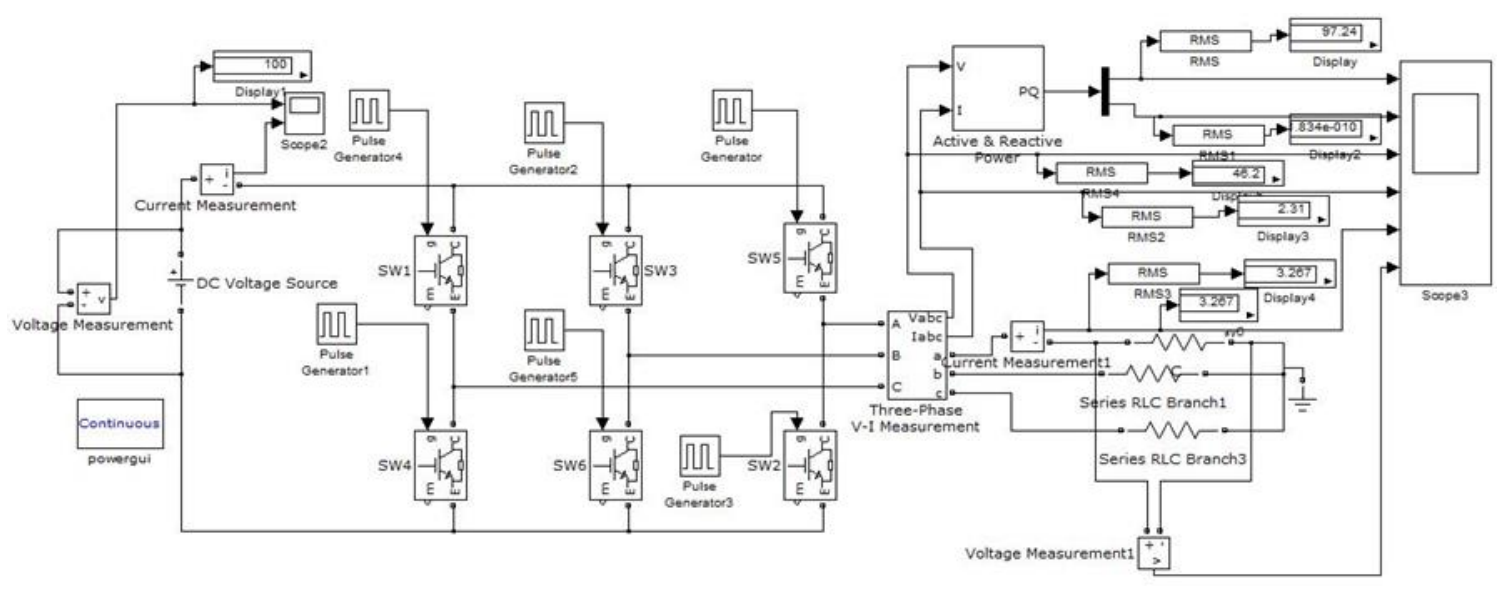

Figure 5. Simulink model of six pulse VSI with resistive load

In second model, VSI is triggered using PWM technique. A complete simulink model is represented in Figure 6. In this triggering technique, IGBTs' switches SW1, SW2 and SW3 are triggered by PWM generator while the IGBTs' switches SW2, SW4 and SW6 are triggered through PWM generator after passing through NOT gate to provide complement signals of PWM generated signals. In Figure 6 PWM generator is shown using its subsystem while detail PWM generator simulink model is further elaborated in Figure 7. Two sine wave signals are added first in which one is working as harmonic signals whose frequency is 3 times of the main sine signal and then compare with the repeating sequence signal after delaying through transport delay.

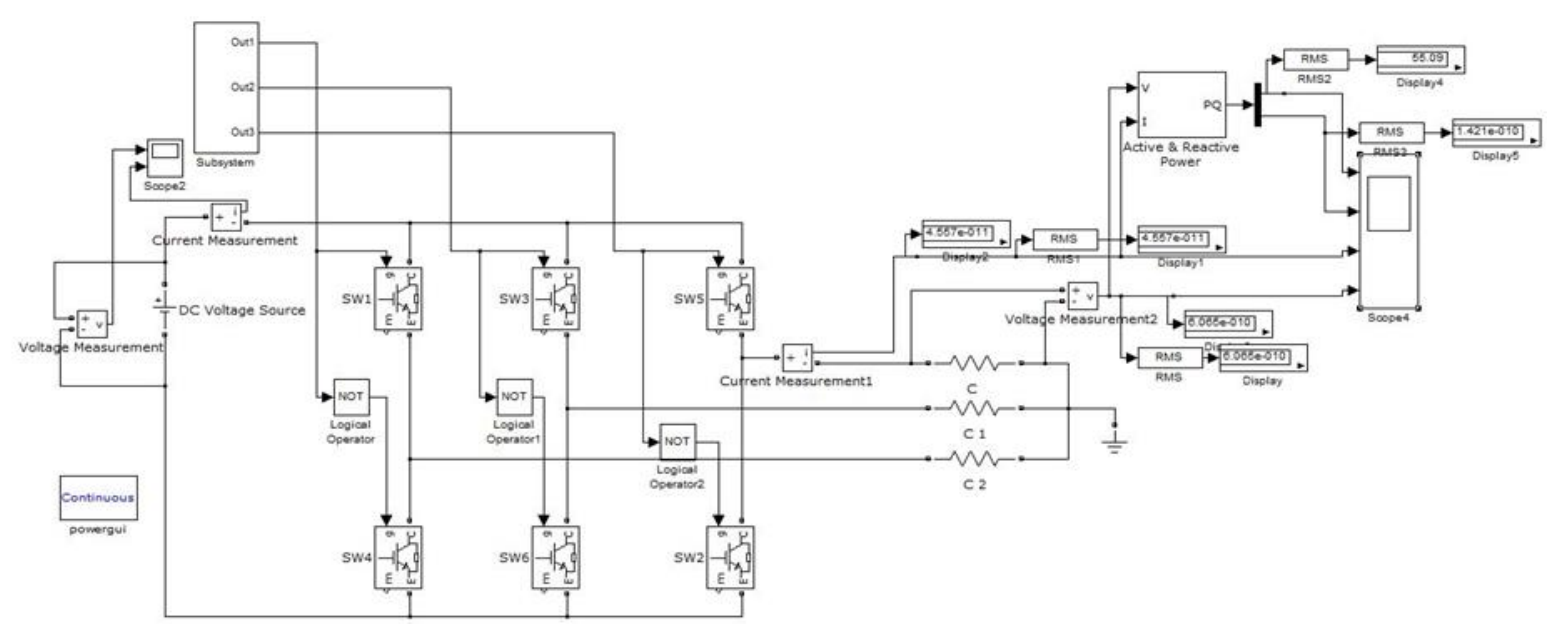

Figure 6. Simulation Diagram of 6-pulse PWM based VSI with R load

IJEEI Vol. 5, No. 2, June 2017 : $108-116$ 


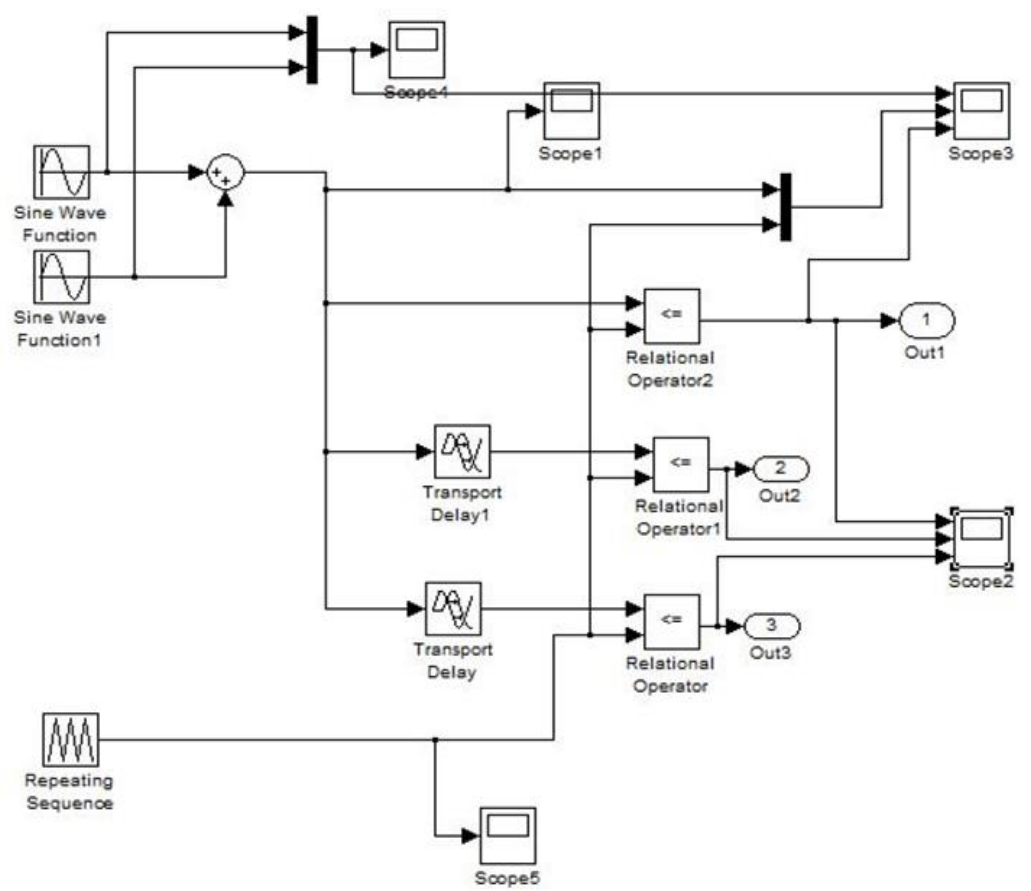

Figure 7. Simulation Diagram of PWM generator

\section{Results and Discussion}

In this paper, STATCOM internal configuration is represented and modeled using MATLAB simulink blockset. This STATCOM is developed with six pulse voltage source inverter circuit. Results for two triggering procedures, conventional and PWM techniques are elaborated for resistive load. A generalized approach is presented to develop STATCOM simulink model that can be expanded for any number of pulses keeping the fact in mind that more pulses can improve the waveform of alternating output. The neccessacity of output performance helps to decide the exact number of pulses of VSI because more pulses includes the power quality problems along with their complex structure.

For six pulse VSI based STATCOM, triggering results by both techniques are compared. Table 6 compares the output voltage, current, real power and reactive power for both the techniques for resistive load of $20 \Omega$. Results are comparable from both the techniques. The results are also verified by their response waveforms. Figure 8 and 9 represent the output voltage and current for conventional triggering and Figure 10 and 11 represent the output voltage and current for PWM technique.

Table 6. Result comparison for conventional and PWM techniques

\begin{tabular}{cccc}
\hline Method of triggering & $\begin{array}{c}\text { DC input voltage } \\
(\mathrm{V})\end{array}$ & $\begin{array}{c}\text { Peak value of } \\
\text { Single phase } \\
\text { output voltage } \\
(\mathrm{V})\end{array}$ & $\begin{array}{c}\text { Peak value of } \\
\text { Single phase } \\
\text { output current } \\
(\mathrm{A})\end{array}$ \\
\hline Conventional & 100 & 65.33 & 3.267 \\
PWM & 100 & 65.33 & 3.267 \\
\hline
\end{tabular}




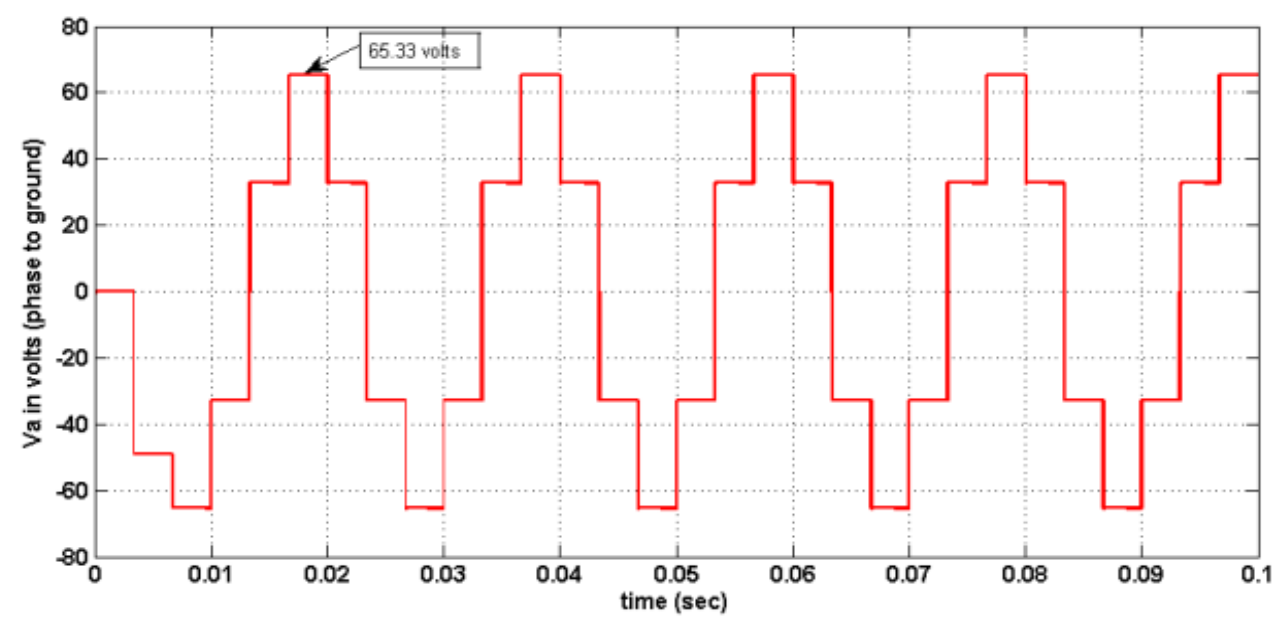

Figure 8. Voltage response of six pulse VSI based STATCOM using conventional triggering

Figure 8 shows that the single phase voltage obtained from conventional triggering and its shape is approaching towards sinusoidal wave in steps with maximum voltage of 65.33 volt (peak value). Figure 9 shows the similar nature of wave with peak value of $3.267 \mathrm{amp}$.

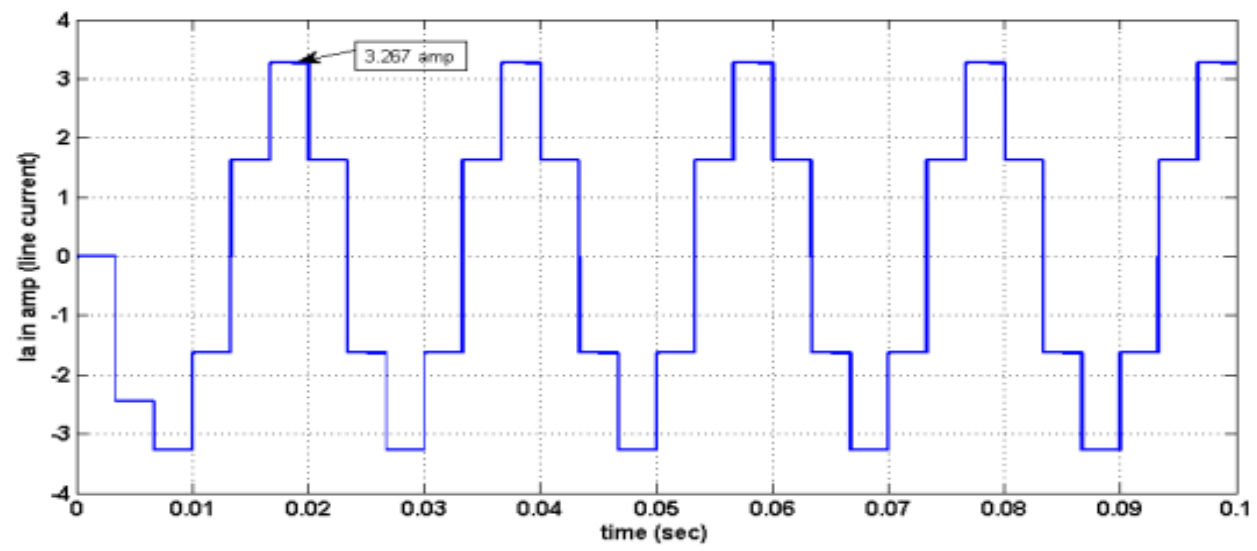

Figure 9. Current response of six pulse VSI based STATCOM using conventional triggering

For triggering through PWM technique, Figure 10 and 11 represent voltage and current responses at output respectively. It must be noted that response is similar to convenmtional triggering exceopt the width of the pulses that make a waveform approaching towards sinusoidal nature. 


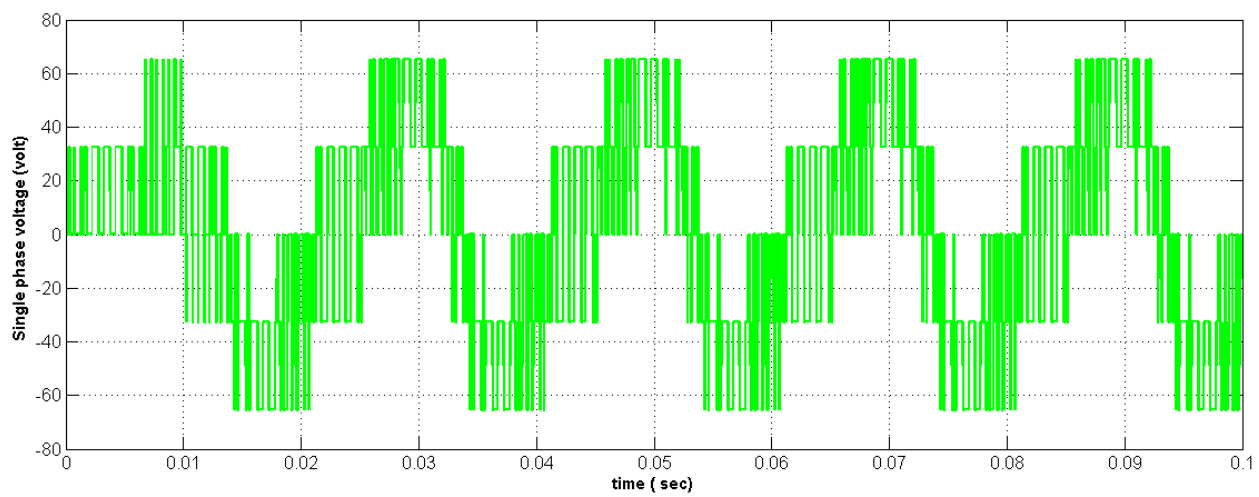

Figure 10. Waveform of phase voltage of six- pulse VSI with Resistive load with PWM triggering.

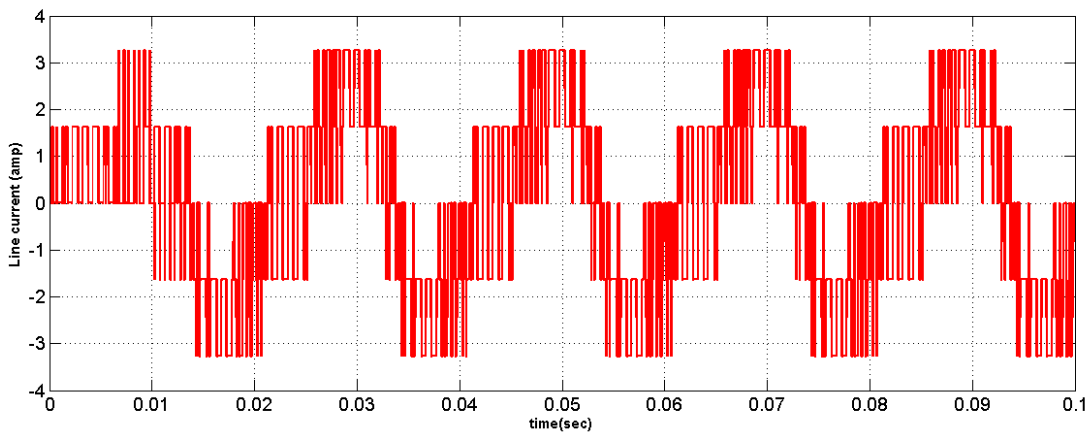

Figure 11. Waveform of phase output line current of six-pulse VSI with Resistive load with PWM triggering.

\section{Conclusion}

Triggering procedures play an important role in modeling and hence a comparative study for two triggering procedures are modeled for six pulse voltage source inverter based STATCOM. Results are compared in terms of output voltage, current, and power. A generalized procedure for developing any number of pulses STATCOM is depicted in this paper. Since in advance power system based studies, STATCOM is one of the frequently used device that helps in voltage control, reactive power compensation and power transfer capability studies, therefore a systematic studies to analyses its model and its expansion is mainly elaborated in this work.

\section{References}

[1] B Suechoey, S Tadsuan and S Bunjongjit. A Comparison of Power Losses and Winding Temperature of Three-phase Induction Motor with PWM Inverter and Six-Step Inverter Supply.

[2] A Boglietti, P Ferraris, M Lazzari and F Profumo. Effect of Different Modulation Index on the Iron Losses in soft Magnetic Materials Supplied by PWM Inverter. IEEE Transaction on Magnetics. 1993; 29(6): 3234-3236.

[3] Mihaela Popescu, Alexandru Bitoleanu, and Mircea Dobriceanu. On the AC-Side Interface Filter in Three-Phase Shunt Active Power Filter Systems. World Academy of Science, Engineering and Technology International Journal of Electrical, Computer, Energetic, Electronic and Communication Engineering. 2010; 4(10).

[4] Yun Xu, Yunping Zou, Wei Chen, Chengzhi Wang, Xiong Liu and Feng Li. A novel STATCOM based on hybrid cascade multilevel inverter. IEEE International Conference on Industrial Technology. 2008.

[5] Sungho Jung and Jung-lk Ha. Low Voltage Modulation Method in Six-step Operation of Three Phase Inverter. 9th International Conference on Power Electronics-ECCE Asia June 1 - 5. 2015 / 63 Convention Center, Seoul, Korea. 
[6] Mohamed H Saied, MZ Mostafa, TM Abdel- Moneim, and HA Yousef. New Three-Level Voltage Source Inverter With Different 25 Space Voltage Vectors. 2006 2nd International Conference on Power Electronics Systems and Applications.

[7] Wang Jinyu, Ye Xitai, Liu Junli. The Research of A Novel Single-Phase Hybrid Asymmetric 6-level Inverter Based on Epwm Control. 2nd International Conference on Measurement, Information and Control. 2013.

[8] Kenta Kawasugi, Shigeo Masukawa. Development of Quasi 24-step Voltage Source Inverter. Department of Electrical and Electronic Engineering, Tokyo Denki University, Japan.

[9] Cheng-Han Hsieh, Tsorng-Juu Liang, Shih-Ming Chen, and Shih-Wen Tsai. Design and Implementation of a Novel Multilevel DC-AC Inverter. IEEE Transactions on Industry Applications.

[10] NNV Surendra Babu, BG Fernandes. Cascaded two-level inverter-based multilevel static VAr compensator using 12-sided polygonal voltage space vector modulation. IET Power Electronics.

[11] A Mahechwari, KDT Ngo. Synthesis of six-step pulsewidth-modulated waveforms with selective harmonic elimination. IEEE Trans. Power Elec.1993; 8(4): 554-561.

[12] KB Khanchandani, MD Singh. Power Electronics Second Edition, Tata McGraw Hill Education Private Limited. 2006: 565-579.

[13] PS Bhimbhra. Power Electronics. Third Edition, Khanna Publishers, 2005: 488-497.

[14] Yanlei Zhao. Design and implementation of inverter in dynamic voltage restorer based on selective harmonic elimination PWM. in DRPT. 2008: 2239 - 2244. 